\title{
A PUBLICIDADE E OS PÚBLICOS NAS REDES DIGITAIS: UMA PROPOSTA ANALÍTICA PARA O MAPEAMENTO DE EMBATES DISCURSIVOS.
}

\author{
Advertising and public on digital networks: an analytical \\ proposal for mapping discursive struggles.
}

\section{La publicidad y público en redes digitales: una propuesta analítica para el mapeo de lucha discursiva.}

\author{
Letícia Alves Lins \\ Universidade Federal de Minas Gerais, Belo Horizonte, Brasil \\ Doutora em Comunicação pela Universidade Federal de Minas Gerais, professora universitária, \\ consultora e mentora, com especialidade em Comunicação, Gênero, Diversidade e Inclusão nas \\ Organizações. E-mail: letslins@gmail.com
}

RESUMO O artigo discute os desafios da publicidade na sua interação com os públicos nas redes digitais e propõe uma metodologia para mapear os embates discursivos ocorridos na interação. Parte-se da hipótese de uma tríade potente entre os conceitos de publicidade, experiência e públicos e faz-se uso do arcabouço teórico do pragmatismo para articular tais conceitos. Analisa-se um caso ocorrido entre a marca de remédios Novalfem e os interagentes do Facebook. A originalidade do trabalho consiste em propor o mapeamento de diferentes lógicas de racionalidade que surgem da interação.

PALAVRAS-CHAVE Publicidade, Experiência, Públicos, Redes digitais, Gênero.

\begin{abstract}
The article discusses the challenges of advertising in its interaction with public on digital networks and proposes a methodology to map the discursive struggles that occurred in the interaction. It was assumed that there is a potent triad among the concepts of advertising, experience and audiences, and uses the theoretical framework of pragmatism to articulate such concepts. A case was analyzed between the brand of medicines Novalfem and the public of Facebook. The originality of the work consists in proposing the mapping of different rationale logics that emerges from the interaction.
\end{abstract}

KEYWORDS Advertising, Experience, Public, Digital social networks, Gender.

RESUMEN Este artículo analiza los desafíos de la publicidad en su interacción con el público en las redes digitales y propone una metodología para mapear los choques discursivos ocurridos en la interacción. Parte de la hipótesis de una potente tríada entre los conceptos de publicidad, experiencia y público y hace uso del marco teórico del pragmatismo para articular dichos conceptos. Se analizó un caso entre la marca de medicamentos Novalfem y los interactuantes de Facebook. La originalidad del trabajo consiste en proponer el mapeo de diferentes lógicas que surgen de la interacción.

PALABRAS-CLAVE Publicidad, Experiencia, Público, Redes Sociales Digitales, Género.

\section{INTRODUÇÃO}

O objetivo deste trabalho é discutir os novos desafios da publicidade na sua interação com os públicos nas redes sociais digitais. Parte-se da 
hipótese de que há uma relação potente entre os conceitos de publicidade, experiência e públicos e um despreparo dessa instituição ${ }^{1}$ em lidar com situações de crise oriundas de sua atuação nas redes. Para tal, propõe-se um outro conceito para se analisar os públicos e uma proposta analítica para se mapear os embates discursivos ocorridos durante a interação.

A primeira parte do artigo discorre sobre o novo momento vivido pela publicidade a partir do conceito de Ecossistema Publicitário, sugerindo a existência de uma instabilidade característica da cultura das marcas na sua relação com os públicos no âmbito das redes sociais.

A segunda seção apresenta os conceitos pragmatistas de experiência e públicos que foram o arcabouço teórico da pesquisa e que são apresentados como uma alternativa viável para se pensar os públicos dentro do novo cenário das tecnologias digitais.

A terceira parte contempla a proposta metodológica criada para analisar os embates discursivos ocorridos entre a publicidade e os públicos nas plataformas digitais a qual pode ser aplicada para a análise de temáticas sociais relevantes.

$\mathrm{Na}$ quarta parte, apresenta-se um estudo de caso ocorrido em 2015 entre a marca de remédios Novalfem e os usuários e as usuárias do Facebook sobre a questão de gênero. Vale pontuar que o ano de 2015 representou um marco para o reaquecimento dos feminismos em rede, situação que foi de encontro com a proposta temática da marca.

Por fim, são elencadas as principais conclusões da pesquisa.

\section{A PUBLICIDADE E SUA RELAÇÃO INSTÁVEL COM OS PÚBLICOS NAS REDES SOCIAIS DIGITAIS}

A publicidade atravessa profundas mudanças, responsáveis por impactar o seu modelo de negócios, o escopo de suas atividades e sua relação com os públicos.

Clotilde Perez (2016, p. 8) faz uso do termo Ecossistema Publicitário com vistas a apresentar um "[...] conceito que se pretende integrador e apaziguador (pelo menos provisoriamente) das tensões, imprecisões e insatisfações com as pesquisas e práticas publicitárias atuais”.

Para a autora, o objetivo máximo da publicidade é construir vínculos de sentido entre pessoas e marcas, e, sendo assim, a proposta do conceito é extrapolar o aprisionamento midiático e transbordar. "As ideias colocadas em prática que busquem essa relação (pessoas-marcas) pertencem ao ecossistema publicitário” (PEREZ, 2016, p. 9).

Sobre a relação entre as pessoas a as marcas, Banet-Weiser e Lapsansky (2008) apontam que a cultura das marcas vive hoje em um estado de fluxo marcado pela instabilidade entre a participação do consumidor e o controle corporativo sobre as mensagens. A tensão é representada por uma luta por apropriação que não ocorre em igualdade de condições, mas acontece em vários níveis que impactam o jogo entre o domínio do mercado e a agência do consumidor, jogo esse que não é sempre equilibrado. Assim, as transformações presenciadas na relação entre os públicos e a publicidade (principal divulgadora da cultura de

1. “[...] um domínio ou campo da vida social identificável que é governado por um determinado conjunto de regras formais e informais, apresenta uma estrutura particular, desempenha determinadas funções sociais, e aloca recursos para a ação social de maneiras variadas” (HJARVARD, 2015, p. 56). 
marca) dão luz à necessidade de as empresas repensarem o tratamento reservado aos públicos e passarem a vê-los como interlocutores ativos que precisam ser respeitados e ouvidos.

Essa realidade se torna mais contundente com a popularização das redes sociais digitais e a consequente necessidade das marcas em ocuparem esse novo habitat. Como pontuam Clotilde Perez e Sérgio Bairon, “[...] se é lá que a vida acontece, as manifestações de marcas e produtos também estarão presentes, uma vez que são expressões socioculturais privilegiadas agora midiatizadas pelo digital” (2014, p. 227).

Silvia Costa (2016, p. 320), ao analisar alguns perfis de empresas nas redes sociais, percebe uma convivência entre anúncios tradicionais e estratégias inovadoras que mesclam entretenimento e assuntos em pauta nas redes sociais. Sobre a opção pelo uso das ações publicitárias convencionais, a autora aponta um crescente descrédito e aversão a esse tipo de apelo por parte de internautas que desejam conteúdos mais interativos. "Se há possibilidade de interação com o conteúdo publicitário [...] as pessoas querem aproveitar essa possibilidade para opinar, questionar, denunciar, endossar, participar”.

Mais do que publicidade e propaganda, Costa (2016, p. 288) pontua a necessidade de se criar comunicação e diálogo, ressaltando que as empresas, além de pensarem formatos de anúncios inovadores para a internet, têm investido na abertura de canais de comunicação e relacionamento com os indivíduos. Sobre os espaços de interação entre as empresas e usuários e usuárias, a autora ressalta a carga de imprevisibilidade característica dessas interações, constituindo-se em locais que as organizações não conseguem controlar por completo. Em casos de desentendimentos, a pesquisadora ressalta a importância da rapidez e transparência na comunicação, “[...] havendo mais lugar para um pedido de desculpas em caso de falhas do que para simulação e diferença”.

Essa nova conformação interativa, imprevisível e contingente, demanda um outro olhar para os públicos, não mais pensados como alvo, mas encarados como voláteis, móveis e oriundos das interações com as propostas marcárias e prontos a formar comunidades de partilha em torno de questões que os afetam com relação às marcas. É exatamente outra mirada para se enxergar os públicos que se discutirá na próxima seção.

\section{A EXPERIÊNCIA E A FORMAÇÃO DE PÚBLICOS}

O arcabouço teórico que iluminou este trabalho foi a perspectiva pragmatista e a abordagem circular da comunicação. Partiu-se da hipótese de uma tríade potente entre os conceitos de publicidade, experiência e públicos e buscou-se analisar os públicos que surgem em interação afetados pelas estratégias publicitárias e se afetando mutuamente.

Usar o arcabouço teórico do pragmatismo - em especial as obras de John Dewey (2008; 2010), de Louis Quéré (2003) e Daniel Cefai (2009) é inovador no campo publicitário, que possui poucos trabalhos com essa abordagem temática. O pragmatismo é uma corrente teórica que busca estudar as pessoas em suas interações intersubjetivas e em suas relações com as coisas do mundo, em ação, ou seja, o interesse é por aquilo que acontece no momento da interação. Iluminado por essa visão acontecimental, o estudo apresentado parte do pressuposto de que as pessoas vivenciam experiências com os produtos publicitários e que essas vivências não podem ser previstas antecipadamente. Além disso, 
ao se relacionarem com as narrativas publicitárias, os indivíduos podem ter experiências positivas e/ou negativas. Quando há um incômodo em relação à temática proposta pelas marcas, normalmente as pessoas reagem e sentem necessidade de se organizarem em públicos para tratarem sistematicamente das questões que as levaram a padecer. Surge, então, uma interação intersubjetiva e uma cobrança de explicação por parte das marcas. A compreensão de que as pessoas vivem experiências com a publicidade e que, uma vez insatisfeitas, formam públicos para tratar sistematicamente as questões representa uma contribuição para os estudos do campo publicitário, o qual, durante muitos anos, se orientou por uma tradição funcionalista que olha para o público como uma entidade fixa e identificada antecipadamente. Daí a força da tríade que propomos como hipótese deste estudo.

O conceito de experiência tem se mostrado bastante promissor para a análise dos diferentes produtos comunicativos que circulam no cotidiano contemporâneo. Em virtude disso, cresce a quantidade de autores e autoras que têm se dedicado a pensar a relação entre a experiência e o processo comunicativo. Estes trabalhos, em sua grande maioria, são inspirados na matriz conceitual de Dewey, que analisa a experiência sob a perspectiva da ação. Para os pragmatistas as experiências surgem das ações vividas entre as pessoas intersubjetivamente e entre as pessoas e as coisas do mundo. Comunicar é fazer experiência e essa se conforma na relação (DEWEY, 2010; FRANÇA, 2016).

Do mesmo modo, a grande referência para se pensar uma nova perspectiva acerca da temática dos públicos é também Dewey, este “[...] forjou um conceito de público que retornou recentemente ao centro dos debates” (CEFAI, 2009, p. 16). A grande visada de Dewey foi inverter a lógica de análise do processo de formação dos públicos e mostrar que estes não são dados a priori e sim surgem em momento de recepção, convocados por determinada situação problemática. Os públicos se dão a ver na interação e constituem-se em todos aqueles afetados direta ou indiretamente por um acontecimento que os concerne e que os faz reunir para tratarem as questões sistematicamente. O conceito de público proposto pelo autor impulsiona um outro olhar para o processo de formação de um coletivo de pessoas. Em sua obra, a formação do público é contingencial e condicionada a acontecimentos.

$\mathrm{Na}$ esteira de Dewey e dando continuidade à sua obra, Louis Quéré (2003) propõe a definição de público como forma. É uma unidade de ordem, conformada por uma vivência em comum. O público é resultado de uma ação, é constituído a partir da experiência de determinada situação. Surge a partir da interpelação de determinado acontecimento ou caso problemático e é agenciado por um contexto institucional, uma vivência que provoca sentido e conclama as pessoas envolvidas a sofrerem juntas a mesma experiência e desejarem compartilhá-la. O autor sugere o uso do termo "em público” ao contrário de “o público”. É preciso identificar os sistemas e agenciamentos em que a experiência tem lugar em público.

Conforme já exposto acima, trabalhar o conceito de experiência e de públicos a partir do viés pragmatista visa se contrapor à perspectiva tradicional funcionalista de "público-alvo"2, de existência independente e

2. A expressão "público-alvo" está destacada entre aspas para marcar que essa é a terminologia e a lógica usadas pelo mercado publicitário para o planejamento de suas estratégias e é exatamente este olhar para os públicos ao qual estamos nos contrapondo, por acreditar que não este atende mais às demandas contemporâneas. 
dada de antemão, tão recorrente nas estratégias publicitárias tradicionais. Acredita-se ser essa uma alternativa bastante pertinente para se pensar a forma como as pessoas lidam com a publicidade dentro do novo cenário de redes sociais digitais. A seguir, será apresentada a operacionalização dos conceitos de experiência e de públicos em um caso específico ocorrido em 2015 e que acionou nas pessoas problemas de gênero. Embora se trate de um estudo de caso, nossa sugestão é que tal proposta analítica possa ser usada no mapeamento de diferentes temáticas sociais relevantes, como as questões de gênero, raça, gordofobia, entre outras.

\section{A PROPOSTA ANALÍTICA}

A metodologia foi dividida em duas etapas: análise de conteúdo e análise qualitativa. A primeira fase buscou a aproximação com o objeto no intuito de deixá-lo falar. Para isso, foi feita a leitura de todos os comentários, criando-se, então, categorias a partir das temáticas que emergiam na conversação. Este exercício possibilitou a aproximação dos temas, de modo a se criar intimidade com as falas. Pode-se dizer que a análise de conteúdo teve um viés quantitativo, uma vez que se procedeu à contagem de quantas vezes algumas temáticas específicas eram citadas no debate. Porém, como esta quantificação foi feita de modo manual pela pesquisadora, não houve a intenção de utilizar-se dos números de modo estatístico, e a estratégia de quantificar as temáticas serviu mais para propiciar alguns referenciais que permitissem uma análise comparativa entre dois quadros.

A segunda etapa consistiu na análise qualitativa dos comentários a partir de uma grade analítica estruturada a partir dos dois conceitos operadores: experiência e públicos.

A operacionalização do conceito de experiência se deu pela apropriação de algumas questões propostas por França (2010): uma experiência comunicativa se dá em interação; as experiências são constituidoras de públicos; é importante olharmos para o terceiro simbolizante, o polo da cultura. Entramos em uma situação de comunicação a partir de um sentido comum partilhado, este não é produzido pela soma das individualidades, mas sim pelos sentidos produzidos socialmente.

O conceito de públicos foi operacionalizado a partir da colocação de Cefai (2009) de que a questão é menos pensarmos "o público e seus problemas” e mais o "problema e seus públicos”. Esta afirmação dialoga com a proposta de Quéré (2003) de que adotemos o termo "em público" no lugar de "o público". Isso significa que é preciso que identifiquemos os sistemas e os agenciamentos em que a experiência tem lugar "em público". Nos interessa descrever e analisar, em situação, a grande confusão de lógicas de racionalidade e de legitimidade que se imbricam em seus cursos de ação e de decifrar os modos de organização da experiência de seus envolvidos (CEFAI, 2009).

Por último, fez-se uso da pergunta norteadora proposta por Goffman (2012, p. 30) “O que está acontecendo aqui?”, para a análise dos quadros de sentido que impulsionaram a polêmica ${ }^{3}$.

3. Goffman (2012) propõe a análise de quadros como uma metodologia para a organização da experiência dos indivíduos. Para ele em toda a experiência vivida as pessoas se deparam com a pergunta “O que está acontecendo aqui?” e é o exercício diário de respondê-la que faz os indivíduos conseguirem se situar no mundo corretamente. 
A grade analítica foi então dividida em três eixos temáticos: o quadro de sentidos; os públicos que se constituem em público e as experiências emergidas da interação.

A seguir será apresentada a operacionalização da proposta analítica no estudo do caso envolvendo a campanha publicitária do remédio Novalfem e os usuários e usuárias do Facebook no ano de $2015^{4}$.

\section{ANÁLISE DO CASO \#SEMMIMIMI}

\section{0 quadro de sentidos}

O Novalfem é um remédio do Laboratório Sanofi, recomendado para febres e dores de leve a moderada intensidade. Em junho de 2015, a Sanofi contratou a agência Publicis Brasil para uma campanha de divulgação desse analgésico. A ideia da campanha partiu de uma pesquisa feita pelo Conectaí, do Ibope Inteligência, que revelou que $75 \%$ das mulheres deixam de cumprir obrigações e 58\% abrem mão de algo que gostam devido a cólicas, dores de cabeça e enxaquecas. Estrelada pela cantora Preta Gil, o mote era brincar com a situação de desconforto das cólicas, dores que acometem a maioria das mulheres no período menstrual. Segundo a própria empresa, "Apostamos em uma linguagem descontraída para falar com uma mulher que é conectada, informada e inteligente" (Natalia Ramos, à época gerente de produto da marca Novalfem, da Sanofi).

O problema se deu devido ao uso inadequado da expressão "mimimi”. Ao tratar as dores como "mimimi", a propaganda interpelou negativamente as pacientes que sofrem de endometriose e têm sérios problemas de saúde devido a essa doença, acionando também as demais mulheres que sentem dores todos os meses. Desconforto esse que, muitas vezes, resulta em danos para a rotina e a qualidade de vida de quem o sente.

A reação entre internautas foi rápida e começaram a surgir vários comentários nas páginas institucionais, ambas no Facebook, do Novalfem ${ }^{5}$ e da agência Publicis 6 .

Em decorrência da polêmica gerada em torno da campanha, no dia 10 de junho, a Novalfem e a Publicis se retrataram nas redes sociais, e a campanha foi retirada do ar.

O comunicado da Novalfem em sua página no Facebook tinha o seguinte teor:

Comunicado. A opinião de nossos consumidores sempre foi importante para nós e, em consideração a eles, decidimos interromper a campanha \#SemMiMiMi, de Novalfem. A campanha surgiu para tratar de um assunto sério de forma mais leve, baseada no humor. Lamentamos, sinceramente, que pessoas tenham se sentido desrespeitadas pela iniciativa pois, de maneira alguma, tivemos a intenção de minimizar ou desqualificar a dor de quem sente.

4. Devido a uma restrição de espaço optamos por apresentar somente a análise qualitativa do caso em estudo.

5. A coleta dos comentários na página de Novalfem foi feita à época em que a polêmica aconteceu. Acesso em: 14 jul. 2015. Logo depois, a marca retirou a página do ar.

6. O post de retratação feito pela agência ainda está acessível para consulta. Disponível em: https://bit.ly/33XC3Ry. Acesso em: 31 maio 2017. 
A nota de esclarecimento ${ }^{7}$ da agência Publicis no Facebook foi a seguinte:

Nota de Esclarecimento. Nosso objetivo com a campanha de Novalfem é ajudar as mulheres que sentem dores leves e moderadas a conseguir manter a rotina e aliviar o desconforto, usando um tom leve para falar de um assunto sério. Em nenhum momento, tivemos a intenção de minimizar as dores das mulheres ou de ofender quem sofre com doenças e problemas mais graves, para os quais a consulta a um médico é sempre aconselhada.

\section{O público que se constitui em público}

O primeiro post analisado refere-se à retratação pública da marca Novalfem, veiculado em sua página do Facebook, no dia 10/06/2015, que recebeu o título de "Comunicado", o qual foi transcrito acima. A discussão em torno desta veiculação durou 15 dias e rendeu 491 comentários $^{8}, 359$ curtidas, 95 compartilhamentos e 15 marcações de outras pessoas. Destas falas, 354 foram de mulheres e 25 de homens, o que aponta uma desigualdade em termos de participação por gênero. Houve também o posicionamento da Associação Portuguesa de Apoio a Mulheres com Endometriose (Mulherendo).

Contudo, a maioria de mulheres e homens estava unida na mesma opinião contra o Novalfem. O diálogo que se deu foi maior com a marca (que não respondeu), mas houve alguma interação entre interagentes também. Embora o comunicado postado pela empresa fosse para noticiar a decisão de retirar a campanha do ar, as pessoas não se ativeram a essa informação e continuaram se manifestando com bastante descontentamento contra a marca. As mulheres exigiam um pedido de desculpas e não apenas um comunicado. A palavra "desculpas" - aceitar que foi um erro - era fundamental para confortar as internautas que se posicionaram.

Alguns comentários revelam que houve um post anterior a este a que se teve acesso e que foi retirado de circulação, além da peça publicitária polêmica, que também foi deletada. Estas duas atitudes irritaram bastante as consumidoras e os consumidores, o que se observa neste comentário9:

acho feio vocês apagarem o post da campanha que recebeu tantas críticas. É assim que querem se retratar com o pessoal? Fingindo que não estão sendo criticados?

Além disso, houve relatos de internautas, durante a conversação, afirmando que a marca estava retirando alguns comentários da conversa, o que irritou pessoas que expressavam sua indignação e sua raiva.

7. É uma prática do mercado publicitário retirar a campanha do ar mediante situações de crise. Sendo assim, como as peças de Novalfem foram retiradas de circulação a análise foi feita pelos comentários dos posts de retratação os quais foi possível recuperar.

8. Dos quais foram analisados os que foram postados nas primeiras 12 horas, que totalizaram 246 comentários e representaram $50 \%$ da amostra.

9. As falas das pessoas foram reproduzidas assim como foram escritas no debate: com erros de português, erros de digitação, abreviações etc. pois não queríamos perder a integridade dos comentários. 
Para a Novalfem dor é coisa séria, e porque não respeitam tbm nossa opnião..cade a liberdade de expressão, nossos comentários foram todos deletados, alem da propaganda preconceituosa e de desculpas esfarrapadas agora se acham no direito de nos calar [...] saibam que temos prints dos comentários feitos... e nao pararemos por aqui $[\ldots]$.

O segundo post analisado refere-se à nota de esclarecimento veiculada pela Publicis, também no dia 10/06/2015, em que a agência buscou se posicionar frente à polêmica instaurada por sua ideia criativa, texto transcrito no item anterior. A nota foi veiculada na página institucional da agência no Facebook, na qual a polêmica aconteceu. Os comentários sobre a nota duraram três dias, e o maior número de falas foi registrado nos dias 10 e 11 de junho, dias subsequentes à polêmica. Os números de engajamento deste post foram: 431 comentários $^{10}$, 239 curtidas, 54 compartilhamentos e 49 marcações. Desse debate participaram 346 mulheres, 61 homens e o Grupo de Apoio às Portadoras de Endometriose e Infertilidade (Endometriose Gapendi).

No espaço aberto aos comentários da página da Publicis houve, também, consenso entre as mulheres e os homens sobre a estratégia criativa equivocada da marca. Neste debate os homens, em sua maioria, se colocaram a favor das mulheres e contra a agência e a empresa, sendo importante frisar que o número de homens que entraram no diálogo para se posicionar foi bem expressivo, 61 . O fato de a Publicis dar o título de "Nota de Esclarecimento" para o seu post incomodou várias pessoas, que exigiram um pedido de desculpas e um posicionamento da agência no sentido de assumir que errou. Nessa página a temática se voltou mais para questões técnicas do campo publicitário.

As semelhanças e as diferenças entre as temáticas surgidas nas duas páginas são descritas a seguir, no terceiro eixo de análise.

\section{As experiências acionadas}

A crítica à estratégia publicitária da agência foi consenso nas duas páginas e entre a grande maioria de internautas. Por se tratar de uma questão relacionada à dor e a um incômodo que só as mulheres sentem, os homens se colocaram muito solidários a respeito e não se sentiram aptos a opinar sobre o assunto. Foram 108 citações contra a publicidade na página da Publicis e 107 na da Novalfem ${ }^{11}$. O modo como essa crítica foi problematizada, porém, difere entre os dois debates. Em Novalfem, a experiência negativa que a propaganda despertou é que foi acionada. Os comentários eram mais emotivos, relatavam experiências próprias, às vezes eram agressivos, percebendo-se uma carga emocional forte nas mensagens. E todos foram feitos por mulheres.

Acho que um comercial que peça desculpa a todas nós mulheres que sofremos de cólica todo mês e já escutamos de VÁRIAS pessoas que é MIMIMI, FRESCURA, e agora por causa de uma propaganda babaca tive que escutar? Viu? Larga esse mimimi! Vocês não imaginam o

10. Dos quais foram analisados 216 , o que representa $50 \%$ da amostra.

11. Esses números referem-se à análise de conteúdo realizada para cada página na primeira fase da metodologia e dizem respeito ao número de vezes cada tema foi citado durante a conversação. 
quanto foram infelizes com essa propaganda. Vocês colaboraram para que aqueles pensamentos babaca de que é FRESCURA fosse alimentado. Desculpa mas um pedido de desculpa no facebook é pouco. [...].

Na página da Publicis, as críticas eram mais profissionais, embasadas em questões técnicas. Mulheres e homens comentaram a falta de cuidado com a estratégia e o despreparo em lidar com a crise.

Gente, contrata consultoria de sociólogos pra ajudar vocês nessas propagandas. Nessa vocês extrapolaram o limite do aceitável. Como consumidora que sangra um rio todo mês e quica de cólica estou ofendida e como cientista social tô pasma com a dificuldade de vocês lerem o tipo de público que tem. Tem que entender que esse modelo de cagação de regra pra mulheres de como a gente deveria se portar hoje em dia não cola, e a reação é imediata com as redes sociais [...].

A falta de experiência para o gerenciamento da crise foi uma questão bastante pontuada na página da Publicis, com 12 citações, e vem ao encontro da hipótese deste trabalho de que, no ano de 2015, as agências estavam despreparadas para lidar com as polêmicas que estouraram nas redes e foram pegas de surpresa.

Gente, nessa agência tem mulher? Se quiserem me contratar pra arrumar essa bagunça, já trabalhei como planejamento, analista de mídias sociais, administrei grandes crises de grandes marcas, já fui revisora de criação. Nunca vi isso que cês tão fazendo na minha vida. Então, melhorem! Agência errou (duas vezes), cliente também.

Este despreparo foi creditado, segundo os comentários, a uma falta de experiência por parte das agências em lidar com a internet. Várias vezes, as agências foram chamadas de retrógradas, por estarem utilizando um modelo de décadas passadas para falar com os públicos das redes. Nove citações de internautas corroboraram a afirmação de Costa (2016) de que o método de aplicar as propagandas tradicionais no âmbito digital é um dos principais erros cometidos pelas empresas ao planejarem publicidade para a internet:

Num mundo onde quase tudo passa por uma camada digital, nunca foi tão importante entender conceitos básicos como empatia, rede, comunidade, contexto social, pesquisa e bom senso. Enfim... uma ideia ruim não fica melhor no digital. Pelo contrário.

O uso da expressão "mimimi” e da hashtag “\#SemMiMiMi” foi o segundo aspecto que mais acionou as pessoas nas duas páginas, com 79 citações na página de Novalfem e 78 na página da Publicis, funcionando como uma expressão gatilho. As pessoas ficaram indignadas e surpresas com o fato de a empresa usar essa palavra, por ser ela sinônimo de frescura e chilique, referência máxima utilizada pelos indivíduos contrários ao movimento feminista para desautorizar sua luta.

'Mimimi' é SEMPRE usado pelos mais desinformados na hora de minimizar alguma causa legítima. E eles usaram esse termo numa campanha, hahahahahahaha... É muita coragem, ein Publicis. Deu certo não. Volte várias casas no jogo. 
As mulheres expressavam seu sentimento de humilhação e raiva, aborrecidas pelo fato de suas dores serem comparadas a um "mimimi".

Pra quem tem endometriose, isso é horrível, ofensivo e desumano!

Eu odiei tanto essa propaganda, é o tipo de coisa que acaba com o dia, era essa a intenção de vocês?

O grupo de mulheres com endometriose constitui um público específico dentre os vários que se formam nas páginas. No debate de Novalfem isso ficou mais perceptível, com 32 citações relacionadas à palavra endometriose, ficando bem evidente o quanto a escolha temática da propaganda feriu essas mulheres. Na página da Publicis essa temática também apareceu, só que em menor quantidade, com seis citações.

Esta é uma doença que acomete várias mulheres e que é descoberta tardiamente, por muitas delas, devido à falta de informação e ao tabu da "frescura”. Sendo assim, o grupo repudiou a campanha, uma vez que a viu como um discurso que ajuda a perpetuar a desinformação. Inclusive, várias organizações de mulheres com endometriose foram citadas no debate e duas delas se pronunciaram a respeito ${ }^{12}$.

O fato de a endometriose levar à infertilidade, caso seja descoberta tardiamente, foi outra temática levantada no debate, tendo quatro citações na página da Novalfem e três na da Publicis. A maternidade é um dos principais papéis sociais atribuídos às mulheres em nossa sociedade patriarcal e um sonho de muitas delas, e, até mesmo por isso, a temática escolhida pela marca fere tão intensamente as portadoras de endometriose que têm problemas de infertilidade.

[...] luto todos os dias contra a endometriose profunda com focos no intestino, uma doença q acaba com os sonhos de todas as mulheres de serem mães, eu venci a infertilidade mais ainda luto contra as dores [...] pelo corpo todo, [...]... então não vem falar q é mimimi.

Ainda com relação ao despreparo da marca e da agência em gerenciar a crise, a resposta padrão elaborada por ambas como solução para a polêmica foi muito criticada, tendo sido citada 37 vezes na página de Novalfem e 49 vezes na página da Publicis. A estratégia pareceu muito pouco para as pessoas que cobraram um "pedido de desculpas" e que as empresas assumissem o erro e não o justificassem.

Se os caras são uma das melhores agências o que custa assumir o erro e bolar uma outra campanha com mais pesquisa e noção do que fala? (rosto com a boca torta).

Esse pedido de desculpas depois de um dia inteiro, com vocês fazendo pouco da biologia feminina mas querendo nosso dinheiro... Precisam fazer mais que isso. Assumam o erro, apaguem tudo logo e peçam desculpas [...].

Nota-se que há um descompasso entre o que as consumidoras esperam de uma publicidade de remédios para cólica e o modo como marca

12. Mulherendo - Associação Portuguesa de Apoio a Mulheres com Endometriose (página de Novalfem); Endometriose Gapendi (página da Publicis). 
e agência pensaram sua estratégia e como as empresas mantêm seu posicionamento durante a polêmica.

Essa inadequação da campanha ao público foi tema que apareceu nos dois debates, com 17 citações na página da Novalfem e 10 na da Publicis. Ou seja, as próprias pessoas sinalizaram isso para a marca.

Se o público-alvo do remédio tá esculachando em massa a propaganda, é porque ela tá toda errada. A pessoa que criou além de não têm útero, empatia e nem bom senso.

Não é argumento que aprende na faculdade... é bom senso, empatia, um pouquinho de conhecimento e cuidado na hora de lidar com determinado público [...] Ficar ganhando prêmio de comunicação não me parece ser o suficiente pra ser considerado o melhor. (Sorriso)

Diante desse descontentamento com a posição assumida pela marca, o boicote ao consumo é reiterado diversas vezes, na página de Novalfem. Foram 36 citações nesse sentido.

Pode ter certeza que terá uma quantidade grande de mulheres boicotando a marca e todos os seus produtos!

Se alguém tem mimimi corre comprar esse remédio, mas se tiverem cólica comprem remédio pra dor.

As consumidoras citaram nomes de remédios concorrentes com os quais elas curam a sua dor, com destaque para o Buscofem que, dias antes, fez outra abordagem para tratar da temática, a qual elas consideraram bem mais respeitosa.

Encontram post do buscofem de alguns dias antes, falando que cólica não é frescura nem mimimi, e esse post é impulsionado nos comentários de novalfem sem parar.

Neste caso, mesmo o post do concorrente sendo impulsionado na página da agência, ela não tomou nenhuma providência. Era exatamente sobre essa falta de iniciativa em lidar com a crise que a internauta estava se expressando.

O machismo estrutural da publicidade é reconhecido como o pano de fundo desse acontecimento. O tema apareceu explicitado nas duas conversações, na página da Novalfem, 25 citações e na da Publicis, 14.

O mundo publicitário é e sempre foi machista mas existe pesquisa de mercado pra evitar equívocos.

Intenção boa? Oxi, foi machismo puro e simples. Desvalorização total dos sofrimentos das mulheres. Foi a opinião dos homens da empresa que acham que mulher é fresca. Empatia zero.

A principal pauta do movimento feminista que apareceu vinculada à questão do machismo foi a igualdade de direitos entre os gêneros no mercado de trabalho. É do conhecimento das pessoas que ali entravam para comentar o fato de que a publicidade, em especial a criação, é uma área ocupada, predominantemente, por homens, fato este questionado por mulheres e 
homens durante o debate, com 23 citações na página da Publicis e 15 citações na página da Novalfem, dado interessante, uma vez que revela haver conhecimento dessa situação, mesmo por parte de não especialistas.

Uma dica: quando pedirem à agência uma campanha voltada apenas para mulheres, evitem uma equipe formada apenas por homens. Por nada.

Né? Mas ainda acho que tem outro problema que se chama 'só tem homem na criação da agência’, vai verão (cara com boca torta).

Os três eixos temáticos que orientaram a análise qualitativa seguem o referencial teórico discutido na seção "A experiência e a formação de públicos” deste artigo. O primeiro eixo, o quadro de sentidos, busca apreender o conceito em que a polêmica se dá. Já o segundo e o terceiro eixo visam articular os conceitos de públicos e experiência sob o viés pragmatista. Esses três eixos em articulação contemplam a base da abordagem relacional da comunicação que promove o diálogo entre o público, as produções discursivas e um contexto institucional que faz sentido (FRANÇA, 2001).

O exercício de fazer esses três eixos dialogarem buscou aproximar o acontecimento de sua completude e tentou radiografar as polêmicas em ação. $O$ que fica evidente na análise é que um público se dá a ver no espaço de comentários de ambas as páginas do Facebook e que esse público partilha sentimentos entre si e se posicionam conjuntamente contra a marca e sua agência. Dentro desse público, vale destacar a ação das portadoras de endometriose que se sentem indignadas com o apelo comunicativo da marca e da agência. Este, com certeza, não foi um público almejado e nem previsto pelas duas empresas e assumiu um papel preponderante no caso. O que nos leva a comprovar nossa hipótese inicial de que, diante das novas possibilidades de sociabilidade oriundas das plataformas digitais, é preciso se alargar a visão de públicos usada pelo mercado publicitário.

Sobre a predominância da concordância entre homens e mulheres nas duas polêmicas é importante ressaltar que, ao que tudo indica, os homens são mais tolerantes às dores físicas das mulheres do que às dores simbólicas. Durante as conversas eles inclusive afirmavam não ter lugar de fala para opinarem sobre esse desconforto.

O mapeamento das principais temáticas discutidas em ambos os debates teve como objetivo detectar as experiências que ali foram trocadas. Como não é possível resgatarmos as experiências no exato momento em que elas emergiram, a estratégia de se fazer uso da linguagem partiu da constatação de Adriano Rodrigues (1991, p. 32) de que a linguagem tem um papel constituidor da experiência humana e "[...] é na e pela linguagem que a experiência se constitui, se revela ou se desvenda o sentido que a enforma” (). Sendo assim, foi a partir do mapeamento das principais temáticas acionadas durante o caso que conseguimos nos aproximar das experiências vividas e compartilhadas.

Dentre as várias temáticas apreendidas na análise, destacamos as críticas das pessoas às estratégias publicitárias, os questionamentos feitos pelos públicos em relação ao despreparo das agências em lidar com a crise e o reconhecimento da inadequação da mensagem para o público. Essas afirmações, vindas da fala das pessoas, servem para reforçar nosso pressuposto de que o mercado publicitário vive uma crise institucional. 
Outro ponto que merece destaque é a expressão gatilho "mimimi" que atua como uma fagulha e aciona negativamente as pessoas, que se sentem impelidas a contestar. A descoberta desse gatilho comprova que as pessoas vivem experiências com as produções publicitárias e estas, não necessariamente, serão sempre positivas. Diante dessas interpelações, é como se um quadro invisível se revelasse e a marca e a agência fossem pegas de surpresa, algo como: mas não podia?

A partir do arcabouço teórico do pragmatismo pudemos mapear as diferentes lógicas de racionalidade surgidas da interação e essa é uma das grandes contribuições desse trabalho.

\section{CONSIDERAÇÕES FINAIS}

A proposta inicial desse estudo foi demonstrar como a instituição publicidade vive hoje um descompasso em relação aos públicos e tem, em muitas situações, dificuldade em lidar com as crises oriundas dos embates simbólicos surgidos a partir da interação com as pessoas especialmente nas redes digitais.

A análise do caso envolvendo o remédio Novalfem e os indivíduos no Facebook só veio confirmar nossa hipótese inicial. Nos dois debates houve um despreparo por parte das marcas e de suas respectivas agências em lidar com a crise. A postura das empresas em justificarem o engano e não assumirem o erro ou se desculparem publicamente levou os textos oficiais a serem alvo de muita indignação e polêmica. Os comunicados padrão de ambas as instituições foram reconhecidos pelas pessoas como uma simples estratégia de colocar panos quentes.

Outro aspecto que ficou evidente foi o desconhecimento por parte dos anunciantes com relação ao problema que as cólicas representam na experiência e na qualidade de vida das mulheres. $\mathrm{O}$ uso inadequado do termo "mimimi” também chama atenção, uma vez que essa expressão é reconhecidamente utilizada pelas pessoas que querem diminuir as lutas das minorias. Isso tudo em um ano que representa um marco no reaquecimento das manifestações dos feminismos nas ruas e nas redes. Os três fatores conjuntamente interpelaram as pessoas e acionaram um contexto institucional que fez sentido e que levou os indivíduos envolvidos a sofrerem juntos a experiência e a desejarem compartilhá-la (QUÉRÉ, 2003).

A sensação que se tem é que a marca e a agência tenham sido tomadas de surpresa diante do embate, como se um quadro invisível e naturalizado se desse a ver diante das contestações. Essa falta de entendimento revelou uma fragilidade no próprio funcionamento das agências. Essas empresas estão habituadas a trabalharem com prazos apertados, sempre com pouco tempo para se aprofundar nas questões sociais mais amplas, e limitadas a uma visão muito estreita de "público-alvo", concepção que não se sustenta mais em uma realidade de redes sociais. A inadequação em lidar com os públicos é inclusive reconhecida e tematizada pelas pessoas.

A metodologia aplicada na pesquisa foi capaz de mapear as diferentes lógicas de racionalidade oriundas do embate entre os públicos e a marca e deflagrar uma crise institucional da publicidade, que precisa rever sua forma e conteúdo no sentido de conversar com uma sociedade mais plural, participativa e diversa. Sendo assim, acredita-se ser essa proposta eficaz para analisar outras situações interativas e revelar temáticas sociais relevantes que necessitam ser problematizadas. 


\section{REFERÊNCIAS}

BANET-WEISER, S.; LAPSANSKY, C. RED is the new black: brand culture, consumer citizenship and political possibility. International Journal of Communication, v. 2, p. 1248-1268, 2008.

CEFAI, D. Como nos mobilizamos? A contribuição de uma abordagem pragmatista para a sociologia da ação coletiva. Dilemas, v. 2, n. 42009.

COSTA, S. Publicidade e mídias sociais: a humanização do discurso como estratégia mercadológica na relação entre empresas e consumidores. In: BEZERRA, B.; GUEDES, B.; COSTA, S. Publicidade e Consumo: entretenimento, infância, mídias sociais. Recife: Editora UFPE, 2016. p. 215-322.

DEWEY, J. A Arte como Experiência. São Paulo: Martins, 2010.

DEWEY, J. Democracia cooperativa: escritos políticos escolhidos de John Dewey: 1927-1939. Organizado por Augusto de Franco e Thamy Pogrebinschi. Porto Alegre: EDIPUCRS, 2008.

FRANÇA, V. V. O objeto e a pesquisa em comunicação: uma abordagem relacional. In: MOURA, C. P.; LOPES, M. I. V. (org.). Pesquisa em Comunicação: metodologias e práticas acadêmicas. Porto Alegre: EDIPUCRS, 2016. p. 153-174.

FRANÇA, V. V. A impessoalidade da experiência e agenciamento dos sujeitos. In: GUIMARÃES, C.; LEAL, B.; MENDONÇA, C. (org.). Entre o sensível e o comunicacional. Belo Horizonte: Autêntica, 2010. p. 39-54.

FRANÇA, V. V. O objeto da comunicação/A comunicação como objeto. In: HOHLFELDT, A.; MARTINO, L. C; FRANÇA, V. V. (org.). Teorias da Comunicação: conceitos, escolas e tendências. Petrópolis: Vozes, 2001. p. 39-60.

GOFFMAN, E. Os quadros da experiência social: uma perspectiva de análise. Petrópolis, RJ: Vozes, 2012.

HJARVARD, S. Da mediação à midiatização: a institucionalização das novas mídias. In: Parágrafo. v. 2, n. 3, p. 51-62, 2015.

QUÉRÉ, L. Le public comme forme et comme modalité d'experience. In: CEFAÏ, D.; PASQUIER, D. (org.). Les sens du public : publics politiques, publics médiatiques. Paris: Presses universitaires de France, 2003. p. 113-134.

PEREZ, C.; BAIRON, S. Redes sociais digitais e publicidade. In: NERY, G. A.; OLIVEIRA, T. M; AZEVEDO, S. T. (org.) Ciberpublicidade: discurso, experiência e consumo na cultura transmidiática. Rio de Janeiro: 2014. p. 213-227.

PEREZ, C. Ecossistema Publicitário: o crescimento sígnico da Publicidade. In: CONGRESSO BRASILEIRO DE CIÊNCIAS DA COMUNICAÇÃO, 39., 2016, São Paulo. Anais [...]. São Paulo: Intercom, 2016.

RODRIGUES, A. D. Arte e experiência. Revista de Comunicação e Linguagem: a experiência estética, Lisboa, n. 12/13, p. 25-33, 1991. 